\title{
Teaching qualitative research in adverse times
}

\author{
Joost Beuving and Geert de Vries
}

\begin{abstract}
This article discusses how the teaching of qualitative research in higher education is threatened by the effects of new public management, by academic culture wars and by a growing belief in big data. The controversy over Alice Goffman's book On the Run presents one recent example of this. In an effort to counterbalance these developments, this article stresses the importance in social science curricula of 'naturalistic inquiry' - the artisanal core of qualitative research. Explicitly acknowledging emic viewpoints, naturalistic inquiry upholds the emancipatory ideal of making society transparent to its members. Teaching naturalistic inquiry as a craft may be the best way to assure 'qualitative literacy' among graduates in their various careers as socially responsible professionals.

\section{KEYWORDS}

ethnography, naturalistic inquiry, public social science, qualitative literacy, qualitative research, teaching
\end{abstract}

This article aims to share a private worry with a larger audience: the erosion of teaching qualitative social research in higher education. Our worry originates in our own experience as social scientists working and teaching at Dutch universities (see also Bal et al. 2014), but we believe that the issue concerns a wider circle of colleagues and peers.

We understand qualitative research in social science as a broad effort to describe, interpret and explain social reality through the medium of language (as opposed to quantitative research, which aims to do so through the medium of mathematics). Qualitative research is a generic social research approach covering a whole gamut of disciplines, including ethnography, anthropological fieldwork, qualitative sociology, organisational fieldwork, interpretive research, oral history, narrative research, and so on. Each of 
these has its own official, disciplinary canon, but, methodologically, they all belong to the same family. Their shared artisanal core is the craft of so-called naturalistic inquiry (Guba and Lincoln 1982).

Naturalistic inquiry may be loosely described as studying people in everyday circumstances by ordinary means. It strives to blend in, to respect people in their daily lives, to take their actions and experiences seriously and to build on these. In naturalistic inquiry, the emic viewpoints of society's members take centre stage. We understand 'society' as Georg Simmel (1950) and Norbert Elias (1998) did: as a network of interdependencies between people. Establishing the boundaries of a particular network is an essential part of the research process. By emic we imply building on people's life-worlds, or, in the vocabulary of the classical anthropologist Bronisław Malinowski (1978), presenting 'the native's point of view'. This does not imply a merely descriptive approach to things social and cultural. As we will argue, description is part of naturalistic inquiry as is interpretation or Verstehen and explanation, developing theoretical or etic ideas about society and its members.

In this article, we first discuss the historical rise and fall of teaching qualitative social research, including a trend towards fragmentation. We consider the recent impact of new public management (NPM) on universities, and we look at the rapidly spreading belief in 'big data' - developments that are detrimental to teaching qualitative research. We illustrate these developments with the fate of Alice Goffman's 2014 book On the Run: Fugitive Life in an American City. Her sustained naturalistic approach has become the object of an academic culture war undermining the status of qualitative research in general. We elaborate on core ideas and practices of naturalistic inquiry and stress the importance of teaching it as a craft. By way of conclusion, we stress the relevance of 'qualitative literacy' (Small 2018) for various professional trajectories of our graduates, both inside and outside academia.

\section{The rise and fall of teaching qualitative research}

In many universities around the world, the teaching of qualitative social research methods has seen a rise and a fall. Having become an established and mature craft in the 1980s, it has lately become a fragmented field lacking focus. Three developments seem to have fostered this trend: fragmentation leading to a narcissism of small differences among scholars and practitioners, NPM's rapid rise in academia, and a strong belief in big data as the way to better understand society. 


\section{Fragmentation of qualitative methods teaching}

From the beginning of academic social science, research approaches have been taught either as part of substantive, disciplinary and thematic courses or as special methods courses. In some countries, for example the Netherlands, specialist courses received an impetus from the creation of separate methodology departments in the wake of the expansion of higher education after the Second World War. New professorial chairs were first created within existing departments (of sociology and psychology in particular) and later in semi-independent methodology departments. The first generation of chairs in social research methodology almost without exception embraced positivism as their guiding paradigm. Typically, they espoused quantitative research designs. Professorial chairs in interpretive, qualitative, or naturalistic inquiry came later and were fewer, both in the Netherlands and elsewhere.

The first specialised qualitative textbooks were written in the vernacular of their respective academic host society, often in syllabus form. Pioneering methodological contributions in the field of qualitative sociology from the 1960s include Barney Glaser and Anselm Strauss's The Discovery of Grounded Theory (1967) and Aaron Cicourel's Method and Measurement in Sociology (1964). This decade also saw the publication of Abraham Kaplan's acclaimed The Conduct of Inquiry: Methodology for Behavioural Sciences (1964), which stimulated further methodological debate. The early 1990s saw a marked change in the production of qualitative methods literature. Its volume increased. Specialist journals enabled the publication of a greater number of articles. At the same time, the internationalisation of academic life de facto meant a focus on an English-speaking research practice and led to the anglicisation of the qualitative methods literature. In the English-speaking world, a number of academic publishers began to position themselves as specialist methods publishers - for example, Sage - opening up an expanding and ever-diversifying market for qualitative methods textbooks. The qualitative methods literature moved away from standardisation: it is now carved up in a number of sub-specialisations and an endless stream of specialist publications, each concerned with one particular aspect of qualitative research. Arguably, the political economy of expansion and specialisation in publishing has fanned the narcissism of minor differences among qualitative researchers. It is not uncommon, for example, to see ethnographers criticising qualitative sociologists for lack of immersion, 'reflexive' practitioners criticising colleagues for being closet positivists and feminist scholars criticising other 
feminist scholars for not being 'intersectional' enough. Under such circumstances, each separate tribe tends to condemn other tribes on the basis of criteria derived from internal navel-gazing.

Whereas in the first decades following the Second World War methods were often not taught as a separate discipline and were either integrated in the supervision of students by senior faculty staff, or not taught at all, we nowadays see how the teaching of qualitative methods is often delegated to junior faculty members. Its descent into the lower university echelons has coincided with - and may be read as a proof of - a loss in status (Van Krieken 2012). Teaching qualitative methods today does not command the esteem associated with courses in, for example, social theory or quantitative methods. Junior teachers of qualitative methods are often inspired to move out of it; they increasingly view their craft as an academic dead end. As one junior colleague confided to us: 'I feel trapped in teaching qualitative research methods, and I fear that it sidelines my career'. Consequently, there is a limited build-up of schools of thought and shared research practices that could work against forces fragmenting qualitative research.

\section{New public management}

Following a worldwide trend, social science at universities is increasingly being subjected to the managerial discourse of accountability, transparency and verifiability, that is, to the demands and constraints of the 'audit society' (Power 1997). This is a consequence of models that were developed for business administration (ultimately based on Taylorist principles of scientific management) being imported into the public sector and also into academic bureaucracies (Hood 1991). Although academic bureaucracies in themselves may contribute to impartiality (Nash 2018), new public management (NPM) implies the curtailing of academic autonomy in research and teaching and creates a separate class of professional managers, thus decoupling administrative decisions from substantive academic concerns (Krause-Jensen and Garsten 2014). A new, administrative elite has quickly established itself, surfing on a wave of political claims of achieving greater outputs while curbing public expenditure. The latter message resonates favourably with many voters, who are invited to associate government expenditure with squandering. NPM has dramatically changed the academic landscape, tending towards a 'corporatisation' of universities (Shear and Zontine 2010; 
Wright and Williams-Ørberg 2008). For our present purpose, we focus on NPM's impact on teaching qualitative research.

First, NPM emphasises rationalisation through a standardisation of academic teaching. The ubiquitous 'study guide' presents a relatively innocent example: different types of courses must all conform to the same mould of educational-science-derived 'atomised' categories and formulations (see Wright and Rabo 2010). For the teaching of qualitative social research, one pernicious consequence is the cutting up of the research process into smaller methods portions. Thus, most social science curricula nowadays have specialised courses in interviewing, the analysis of qualitative data, making observations, and so on. Yet a danger of thus cutting up qualitative research is that it compromises the idea of iteration: in the practice of qualitative research and especially of naturalistic inquiry, researchers move between different phases, combining theoretical reflection with data collection, and with the grounding of new ideas in those data.

Second, in their search for an ever more rational (that is, efficient) meansends relation between teaching effort and teaching output, NPM-inspired managers look for economies of scale and find these in the lecture format. From a managerial viewpoint, lectures present a scale-free mode of knowledge transfer: the content of the teaching is not affected by the size of the audience addressed. And, of course, increasing the number of students per teacher is an easy way to curb operational teaching costs. A recent development in this regard is the recording and distribution of lectures via the internet so that students can review them at their convenience, for example, in the form of 'knowledge clips'. A major challenge in teaching qualitative research, however, is that its skills cannot be packaged for large-scale lecture settings without losing substance. Ideally, qualitative research is taught hands-on in a master-apprenticeship relation that thrives in a small setting. Central to learning the craft is gaining first-hand experience with doing fieldwork, which is impossible in a lecture hall setting. ${ }^{1}$

Third, to assess the outcomes of teaching (and hence of the expenditure of public funds), NPM objectifies those through mostly quantitative indicators. Yet qualitative research methods are used to study how order in society emerges from below as a consequence of how people define their situations. Assessing student work, therefore, revolves around a question that is both broad and fundamental: to what extent have students done justice to the process of the social construction of reality? How have they captured society's emic viewpoints and how has their sociological or anthropological 
imagination aided in that? This encompassing aim is difficult to formalise, count and add up in the sense implied in NPM.

\section{Big data}

Another positivist discourse that the teaching of qualitative research has to confront is that of big data. In spite of its surging popularity, the term itself lacks precision (Mayer-Schönberger and Cukie 2013). Some point to the sheer volume and complexity of data following from the rapid expansion of the internet since the 1990s, challenging conventional, statistical methods of data analysis. Others have argued that big data signifies a shift not in the type of data but in their governance, from the state to the market. The gathering, analysing and safeguarding of information about people as citizens used to be the responsibility of nation-states (Scott 1998), but these are increasingly being replaced by large corporations that trade in consumer data: such data have become big business and are increasingly mobilised for political purposes (Cadwalladr 2017; Grassegger and Kocherus 2017). This shift may turn out to be more consequential than the increase in data volume per se.

For the purpose of teaching, a second and (even) more pertinent point is whether large datasets provide hitherto inaccessible ways of understanding society and its members. This would be a positivist dream come true making obsolete the painstaking exploration of emic worldviews that constitutes the trading stock of qualitative research. We argue that this view rests on misconceptions of social reality and how best to grasp it, the resolution of which should find its way into teaching. Data can become meaningful only through interpretation (Wang 2016). What do the data - or rather, the actions and feelings from which they have been constructed - mean to people who produce them and who are affected by them? And how do they fit in a more general framework that considers the nature of society and the direction in which it is evolving? Big data may be good at describing vast amounts of social facts (Durkheim) or 'objectivations' (objective consequences of human actions) (Berger and Luckmann [1967] 1991), but they are bad at reconstructing the definitions of the situation (Thomas and Thomas 1928) from which these social facts emanate. Big data are both insensitive to and silent on emic meanings of situations. Of course, rational choice theory, the theoretical orientation that seems to have the strongest affinity with big data, tries to overcome this problem by postulating that all human action should be understood as a form of utility maximisation in an environment structured 
by incentives and bounded by scarce information about the situation. This is a highly 'totalitarian' approach to emic meaning or, as Jürgen Habermas (1984) would have it, a colonisation of people's life-worlds by economics and social science (and as argued above, increasingly by the market-politico complex). To uncover the multiple meanings of situations and the diversity of human actions following from them, qualitative research with its attention to motivations and self-definitions remains essential. To be understandable at all, 'big' data need the 'small' data of qualitative research (Lindstrom 2016), ideally combined into 'symphonic social science' (Halford and Savage 2017).

Lastly, contrary to the claim that in our era of planet-wide connectedness big data represents the totality of humanity, in reality its scope is far more limited. Within the Western world, marginalised groups with weak linkages to mainstream society tend to be underrepresented. One needs to have money, a credit/debit card, computer literacy and a digital device to make online purchases. Many Westerners do not meet these requirements and remain under the radar of big data collection. In developing countries, only a minority of the population owns a functioning mobile phone and enjoys the wonders of wireless internet connections. From a big data perspective, Paul Collier's (2007) 'bottom billion' is a gross underestimation: no fewer than four billion people in the world live offline (ITU 2015). Their lives are not captured in big data. Big data thus present a severely skewed picture of the world. This will continue to be true even if and when billions more people start using smartphones, as the use of digital devices will still not be equally distributed.

\section{Alice Goffman's On the Run}

Let us present a case study, one specific example of both the strengths of qualitative research and the strains that this type of research is under. Alice Goffman's ethnography On the Run: Fugitive Life in an American City (2014) discusses the fate of a black underclass in a US city, many of whom live off the spoils of the local drugs economy. The book is the result of sustained, extensive and intensive fieldwork, begun as an undergraduate assignment, continued as graduate work, published in part in the American Sociological Review, defended in full as a doctoral thesis, and eventually published commercially. As her publisher, the University of Chicago Press summarises the book's core conclusion: 'The War on Drugs has . . created a little-known surveillance state in America's most disadvantaged neighborhoods. Arrest 
quotas and high-tech surveillance techniques criminalize entire blocks and transform the very associations that should stabilize young lives - family, relationships, jobs - into liabilities, as the police use such relationships to track down suspects, demand information, and threaten consequences'. Along the way, Goffman collected ASA awards for the best article (2010) and the best doctoral dissertation (2011), and praise from leading sociologists and public intellectuals like Cornell West, Elijah Anderson, Howard Becker and Malcolm Gladwell. We feel the praise is fully deserved. Measured by core criteria of qualitative research - initial heuristic openness, thorough immersion through fieldwork, gradual saturation, sustained reflexivity, insightful interpretation of emic perspectives, convincing grounded theory, superb writing throughout - the book is a masterpiece. It ticks all our boxes and more. For example, the way Goffman made her informants co-owners of the book and shares royalties with them is admirable. We have begun and will continue to read and discuss the book with our students and $\mathrm{PhD}$ candidates.

It comes as a surprise then that Goffman has become the object of a sudden surge of criticism - some of it anonymous. ${ }^{2}$ Her data have been questioned as insufficiently quantitative (but of course she is an ethnographer). She has been accused of being unreflexive of her 'positionality' and her 'white privilege' (even though the book and the methodological appendix give highly insightful and self-critical reflections on possible effects on the field situation of her own middle-class position, her white ethnicity and her female gender). She has been grilled for minor inconsistencies in the text (which she has admitted and explained as due to repeated rewriting of the manuscript); and of course, she has been symbolically excommunicated by critics attaching the stigma of 'journalism' to her work (which it is clearly not).

Where do these criticisms come from? How can we understand their ferocity? What does it mean that a piece of work that is considered excellent by social-scientific heavyweights (and by us) evokes such fierce and to some extent vicious criticism from other members of the same academic community? We feel that the answer must be sought in tensions within that community not unlike the ones discussed in the previous paragraph and also in pressures on that community from outside. As Gideon Lewis-Kraus (2016: 16) writes: 'Sociology is a fractured field . . . that has gone through cycles of tribalism. . . . Goffman became a proxy for old and unsettled arguments about ethnography that extended far beyond her own particular case'. And: 'When the politics of representation have become so fraught, who gets 
to write about whom?' We have already mentioned the tendencies toward fragmentation, narcissism of small differences, and navel-gazing. They seem to be particularly strong in the United States but they are visible in the Netherlands too. Lewis-Kraus also asks: 'What is the continuing role of the qualitative in an era devoted to data?' This echoes our own observation that the advent of big data feeds renewed positivist attacks on qualitative research - at least by some.

Furthermore, Lewis-Kraus touches on something not previously mentioned in this article: the fact that academic discussions are now more public than they have ever been before. An anonymous interviewee observes: 'This is the first time the debate is being carried out in the Twitter age'. LewisKraus suggests that precisely the media publicity has made the discussions so personal and so nasty. This seems part of a broader trend: the trust of the general public in science - be it climate science or agricultural genetics or ethnography - can no longer be taken for granted, and many of our academic discussions are nowadays conducted in the public eye. This puts extra pressure on all academics involved. Ideally, of course, they should unite around their common stock of knowledge and present this transparently to the wider world. Perhaps inadvertently, social scientists may seek refuge behind (or overly rely on) the positivist paradigm of natural sciences in order to convince their audience. And, unfortunately, some of them may also be tempted to try to delegitimise colleagues' work in the eyes of the public, thus 'exporting' intra-academic quarrels into the public arena.

\section{The craft of naturalistic inquiry}

To strengthen the case for qualitative research in social science curricula, it may be helpful to review the artisanal core that underpins it: the craft of naturalistic inquiry (Guba and Lincoln 1982). Unlike many conventional approaches in social research, naturalistic inquiry rests on a direct engagement with society by doing fieldwork: studying people in everyday circumstances by ordinary means. 'Ordinary' here means taking part in people's daily lives instead of merely observing these lives; having casual conversations with them instead of formal interviews; participating in people's networks and studying those from within, rather than trying to map them from inventories and so on. The instruments of the researcher should be as pedestrian, unobtrusive and 'ecologically valid' (Neisser 1976: 33) as possible. Naturalistic inquiry takes seriously the emic worldviews of the members of a society 
rather than imputing external frames of meaning or significance to them. Acknowledging these views enables more valid and robust forms of social understanding, grounded in lived experience and in real, observable social practice. Teaching the craft of naturalistic inquiry to students is one way of teaching 'interpretatively' (Dodge et al. 2016).

\section{The arc of naturalistic inquiry}

Naturalistic inquiry may be thought of as following an arc (Figure 1). It begins with a loose idea of the problem being studied: in Bronisław Malinowski's words, the 'foreshadowed problem' (Malinowski 1978). The problem usually begins its life as a loose collection of ideas, some only sketchy snippets based on common sense, others more elaborate and drawn from socio-scientific literature. Gradually, these solidify into sensitizing concepts (Blumer 1954), tentative propositions developed further by fieldworkers immersing themselves in the everyday life of the persons and societies of interest. This is the fieldwork part of naturalistic inquiry usually associated with methods: observing social practices (participant observation), talking to people (interviews), taking stock of the web of social relations in which these

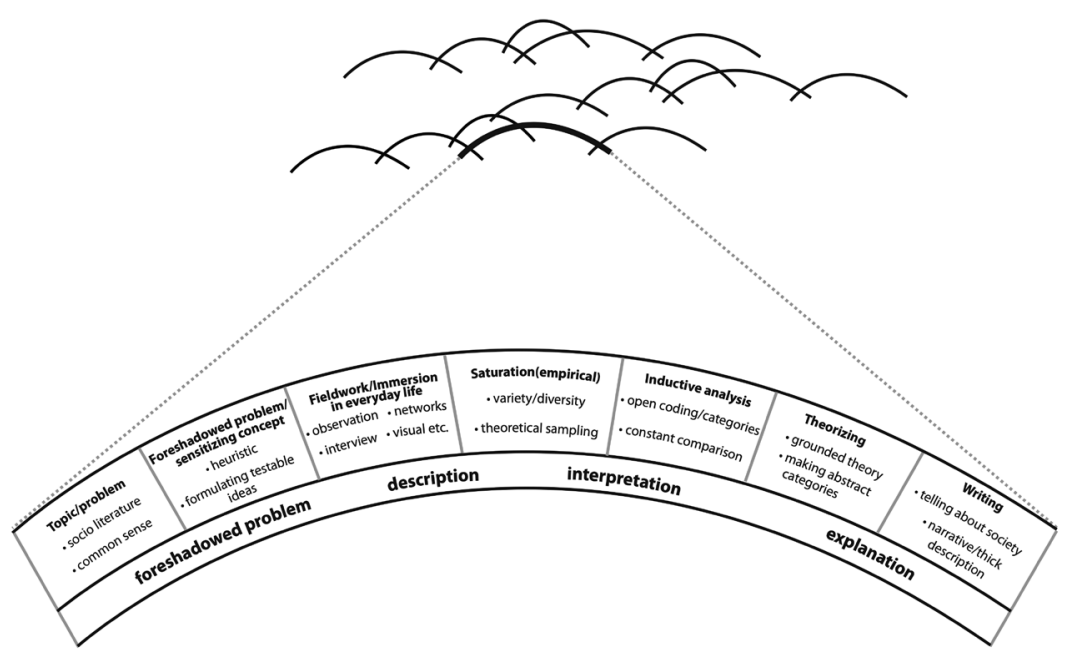

Figure 1. The arc of naturalistic inquiry. Source: Beuving and de Vries 2015: 17. 
people are embedded (network analysis), considering the infrastructural and architectural environments in which they live, watching documentaries, reading literature (including fiction) relevant to the case, and so on.

After a while, the learning curve, which is steep initially, begins to level off. Additional observations no longer yield additional insights, and conversations with informants become repetitive or even boring. Although this is a negative sentiment, in fact it is a good thing as it signals empirical saturation: a point beyond which few extra insights can be expected from further fieldwork. The researcher then enters a next phase: that of theorising. Theorising requires a shift not so much in practical organisation as in intellectual attitude: from being a sponge soaking up impression after impression to being a detective sifting actively and analytically through empirical material in order to detect patterns.

As most qualitative researchers know and practice, this begins with breaking down the passages from one's field notes into meaningful units, which are then tagged with a code. After working through the field notes, the researcher regroups the totality of codes into units of a higher level of abstraction, usually called categories or axial codes (Strauss and Corbin 1998). A subsequent step consists of considering relations between these categories and specifying these relations. This brings the research to the level of abstraction associated with theory (Kaplan 1964). Theoretical concepts constitute the building blocks for 'telling about society': the representation of society in a condensed, scientifically informed, yet accessible narrative (Becker 2007). As a final step, the researcher writes about society, usually in the form of a thick description (Geertz 1993), an empirically dense story organised and enlightened through theoretical insights.

The metaphor of the arc symbolises the distance travelled by naturalistic inquirers. They eventually return to their initial problem, but not to the same spot from which they started. They have carried the problem further and provided new, deeper insight into it. This is why we prefer the image of an arc to the more conventional image of a research cycle (see also O'Dell and Willim 2015). We have drawn the arc of naturalistic inquiry as one enlargement out of a totality of inquiries. A single scientific study is sometimes one of a much larger number of studies, being conducted both simultaneously and consecutively by other researchers. It is a contribution to that number. Apart from providing the most convincing explanation of their own problem (their own facet), naturalistic researchers must ask themselves how their contribution relates to the field of research as a whole. 
Of course, the arc of naturalistic inquiry represents a stylised version of the successive steps a researcher takes. Whereas analytically the steps follow one another in a directional and cumulative manner, in practice the researcher typically takes two steps forward and one step back, only gradually moving from the left to the right along the arc. This is known as iteration, a typical characteristic of qualitative research.

\section{Describing, Verstehen, and explaining}

Moving along the arc, what do researchers do from an epistemological point of view? In the early stages of research, they typically describe (Figure 2). This often begins as a travelogue: seeing and recording society through the eyes of a slightly bemused, yet sympathetic, visitor. This may take the form of a 'grand tour', an initial survey of stuff that can be observed by anyone who cares to pause and look at society (Spradley 1980). Ideally, the researcher carefully observes people and their actions but deliberately refrains from making strong assumptions about their motives. Exploring motives is the next step wherein the emic views of members of society come into play. This is the task of interpretation or Verstehen. In the recording of field notes, this can be observed when the pages of a notebook begin to fill up with informants' statements, allowing the researcher to gauge their experiences

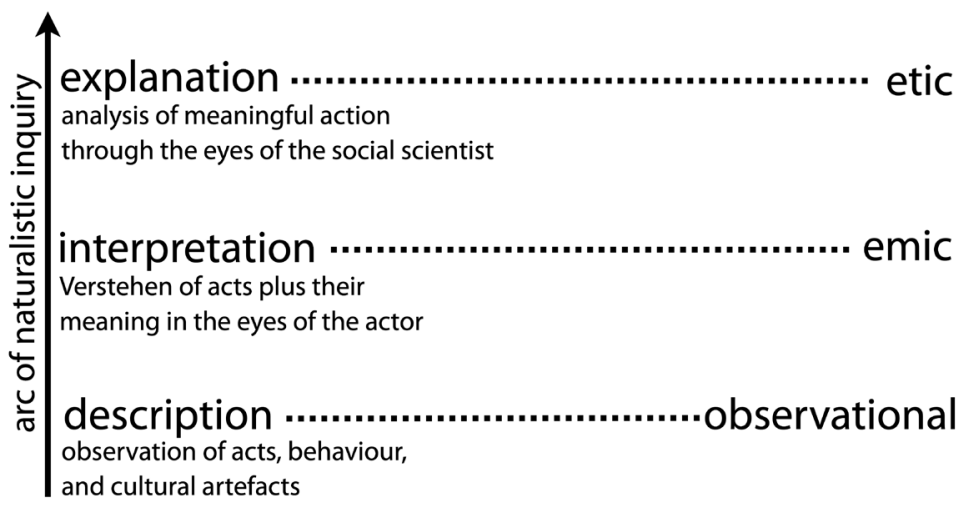

Figure 2. Description, interpretation, and explanation. Source: Beuving and de Vries 2015: 30. 
and motives. Soon after, the researcher begins to discover how informants may disagree over the same event or phenomenon; this is an indication that the fieldworker is moving beyond the early monolithic view of a society that characterises the early travelogue.

All along, the researcher looks for points of engagement between empirical findings and the socio-scientific literature, but this intensifies once the data collection is becoming saturated. In naturalistic inquiry, academic literature is both a source of inspiration and a frame of reference for reflection. It is important to clarify the term 'theory', as it easily conjures up an image of difficult introspection and complicated language that only privileged insiders can hope to grasp. In naturalistic inquiry, however, the authors refer to adopt a processual idea of theory (Swedberg 2016). Through theorising, the researcher abstracts from everyday reality and starts thinking in terms of categories of phenomena and the relations between them. Theorising is not limited to socio-scientific practice; rather, it is central to everyday life (see also Berger and Luckmann [1967] 1991). Social theory in naturalistic inquiry is special in that it helps to develop a more general language of society with a view to generalising from the empirical cases studied.

The form of theorising mostly associated with naturalistic inquiry is that of grounded theory. Grounded theory has nowadays become a catch-all term (Zussman 2004) but, historically, grounded theory emerged in direct opposition to positivism (Glaser and Strauss 1967). It can also be viewed as a reaction to both 'abstracted empiricism' and 'grand theory', famously criticised by C. W. Mills (1959). Whereas the former reduces theory to a store of testable descriptive hypotheses, the latter provides a 'totalising' view on society, considering the social experience of its members irrelevant. Grounded theory explicitly begins with these experiences and builds on them. It seeks to tell about society by aligning particular, individual experiences with broader processes of societal continuity and change. In the process, it respects people's emic webs of meanings (Geertz 1993), yet adds to them by connecting them to broader, socio-scientific webs of theoretical significance. The latter, of course, is also known as explanation.

\section{The social construction of reality}

Another way to clarify the epistemological stance of naturalistic inquiry (and of qualitative research in general) is to stress its debt to symbolical interactionism. It subscribes to the Thomas theorem: 'If men [i.e. people] define 
situations as real, they are real in their consequences' (Thomas and Thomas 1928: 32). Naturalistic inquiry studies the social construction of reality by reflexively watching and participating in the process. People define situations as real and they act accordingly, thereby creating Durkheimian 'social facts'. These social facts are of course also known as institutions. A key task of naturalistic inquiry, therefore, is to understand meanings and the social facts that emanate from those, but also to understand how these social facts in their turn precondition new meanings, that is, new definitions of situations. Acts and meanings thus interact constantly, and researchers should think of them in a time perspective. Today's definitions of situations are tomorrow's social facts, and tomorrow's social facts precondition the day after tomorrow's definitions of situations (see Figure 3).

This processual view of society is the epistemological core of teaching naturalistic inquiry, and it directs the attention of students to the relation between action and meaning; neither of them exists independent of the other. In the spirit of naturalistic inquiry, fieldwork constitutes the best route into grasping that. Fieldwork forces students to see the Thomas theorem in action, as they must grasp life-worlds that are usually different from their own. This entails participating in the lives of informants, sitting down with them, and exploring how they look at their world. In teaching naturalistic inquiry, we must encourage modesty, postponement of normative judgement and cultivation of genuine interest in the lives of other people, however different they may be from the researcher's own life.

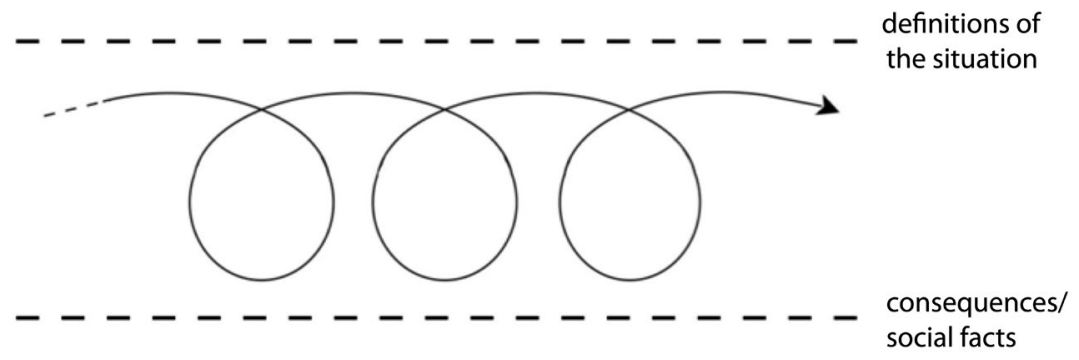

Figure 3. Definitions of the social situation and social facts. Source: Beuving and de Vries 2015: 33. 


\section{Writing}

Last but not least, writing is an essential part of the craft of naturalistic inquiry. Writing often has the positivist connotation of 'writing up' findings from research. Or it has the literary-philosophical connotation of crafting beautiful sentences from a vocabulary associated with high theorising. Neither is advocated in naturalistic inquiry. Writing in naturalistic inquiry best takes the form of 'thick description', which combines description with interpretation and explanation. Thick description should thus select a language that allows the reporting of social facts, that does justice to the informants' emic views, and that can additionally convey the etic, theoretical insights inferred from those (see Figure 4). The latter should never prevail to the extent that they overwhelm informants' meanings. Instead, they should help the researcher to understand their understandings. One could say that good explanations are socio-scientific understandings of everyday understandings; or as Max Weber famously proposed: 'A science which attempts the interpretive understanding of social action in order thereby to arrive at a causal explanation of its course and effects' (Weber 1947: 88). The reverse is also true: thick description without a theoretical point is lacking in sociological or anthropological imagination (Mills 1959).

Regrettably, writing has taken a back seat on socio-scientific curricula. These reflect a greater fascination with the world of numbers and statistical analysis than with words and their symbolic meanings. We have nothing

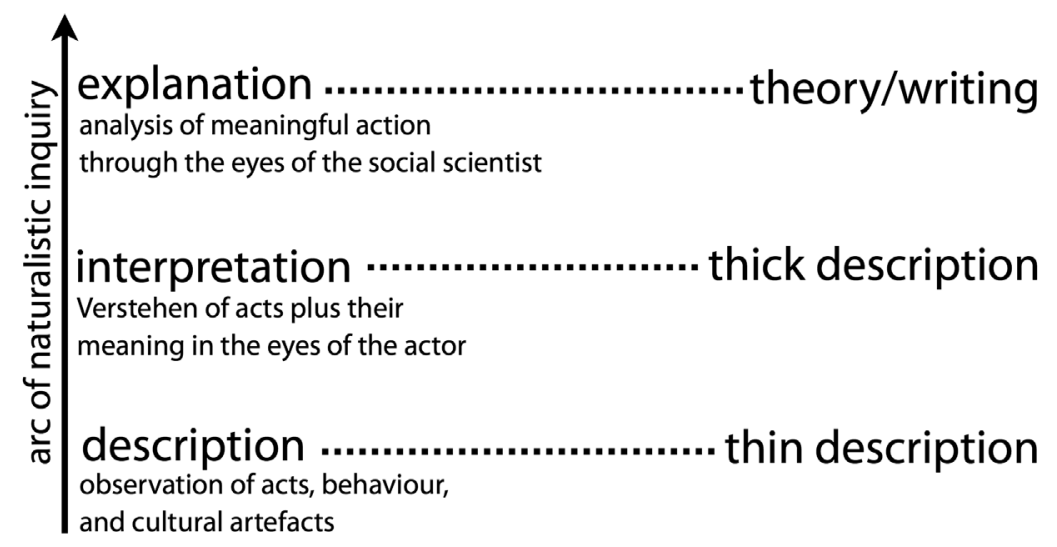

Figure 4. Thin description, thick description, and theory writing. Source: Beuving and de Vries 2015: 30. 
against quantitative research, but many symbolic aspects of everyday life defy simple quantification. For instance, emotions such as jealousy and shame are difficult to gauge in a survey. Writing is thus key to naturalistic work, and we advise students to write throughout all stages of the arc of naturalistic inquiry. To structure that, a distinction may be made between purely descriptive statements about informants and their actions to which no meanings can be imputed yet. This is also referred to as 'thin' description. Next follows a mode of writing that focuses on actions plus their meaning in the eyes of the actor: writing from the informants' point of view. This is where informants become visible by commenting on the things they do and the people with whom they surround themselves. In the final stage of the writing - the explanation - the author takes over again, connecting the ambitions, expectations and other meaningful aspects of informants' everyday lives to debates in the social sciences.

\section{Teaching qualitative research as a craft}

With the above in mind, we would like to make two final points - one about teaching qualitative research and the other about the importance of 'qualitative literacy' for graduates with careers both inside and outside academia. The expression 'qualitative literacy' arose between the two of us while writing and editing this article. We would broadly define it as the ability to view society through the eyes of its members and to take their emic worldviews seriously. Searching the internet, we found one scholar having already used the term in a public lecture. Mario Luis Small understands by qualitative literacy: 'the ability to understand, handle, and properly interpret qualitative evidence'. He adds that 'it can only be acquired through practice; it results ultimately from the habits of thoughts people accumulate over years of experiencing handling these kinds of data' (Small 2018: 2, original emphasis). This is a good introduction to both points below. First, naturalistic inquiry and more generally qualitative research is a craft that requires guided practice. The example that comes to mind is that of the apprentice carpenter who learns to master the craft of making a chair. Of course, he can nowadays download an instruction manual from the internet, procure timber from a local wood shop, and begin his work. However, the chances are slim that this will result in a good chair. His learning will improve greatly if he first observes how an experienced craftsman makes a chair, familiarising himself with the basic steps. Perhaps the craftsman comments on his own work 
so that gradually the apprentice becomes aware of the multitude of small and larger decisions that go into it: the type and structure of the wood and its degree of dryness; the type of equipment needed at every stage of chair making; the type of glue and the time needed for it to set; and so on. As a next step, roles reverse. The apprentice takes the lead in building a chair and the experienced craftsman now functions as a coach. Soliciting comments regularly at the early stages of the role reversal, eventually the apprentice works independently, with the craftsman casting an occasional eye on the apprentice who is now becoming a craftsman himself.

Obviously, the first stages of this model are difficult to achieve in teaching naturalistic inquiry: rarely do students get a chance to directly observe experienced naturalistic inquirers carrying out their craft. Inviting researchers to expand on the decisions that went into their work can compensate for this to some extent. Not all researchers who are good or even brilliant craftspeople are able to do this, though. For some, the craft of naturalistic inquiry is tacit knowledge. Many, though, are highly reflexive practitioners who are happy to share their experiences and anxieties with students.

The second part of the craft-based teaching model can be emulated in regular (ideally weekly) research seminars wherein students share their workin-progress with peers and teachers. (Another mode consists of visiting students while they are undertaking fieldwork; however, this may compromise the naturalistic ambition of naturalistic inquiry: to reduce obtrusion of the research situation to a minimum.) From this - admittedly idealised - model, it follows that teaching naturalistic inquiry takes time and requires focus and concentration, especially initially. Naturalistic inquiry is slow social science and it must also involve slow teaching. ${ }^{3}$ It is difficult to imagine how this can be achieved in a short methods course without allowing students to go through the entire arc, from problem intuition via fieldwork through analysis and writing grounded theory.

\section{Imparting qualitative literacy}

A second point: the students we teach become members of the intellectual, professional and sometimes political vanguard of our society. The image of society that they build up during their studies will influence how they engage in it. Only a small minority of social science graduates remain within academia by pursuing a doctorate and becoming researchers and 
teachers at universities. They become members of our own community so to speak. Evidently, it is important that they should be taught the craft of naturalistic inquiry and be able to pass on Malinowski's heritage. Their own post-graduate research will further complete, strengthen and deepen their craftsmanship. However, the majority of today's graduates pursue careers outside academia. What they have been taught in university about qualitative research - their qualitative literacy - will have to last a lifetime. Paradoxically, that makes our teaching even more important. How can our teaching of qualitative research improve their standing as socially critical professionals? Let us by way of examples look at three extra-academic fields of employment of social science graduates. ${ }^{4}$

\section{Advocacy work}

Many social science alumni try to remedy the problems of society through campaigning, lobbying and seeking media attention. They try to influence decisions of those in power: corporate leaders, politicians, the legislature. Advocacy work typically finds inspiration in critical discourse, such as expressed in the social theories of the Frankfurter Schule, Pierre Bourdieu, or Sheila Benhabib, just to name three. These thinkers are generally dissatisfied with society's status quo and point to how those in command legitimise inequalities by naturalising them. Advocacy work capitalises on that by unveiling mechanisms sustaining powerful positions - like authoritarianism, symbolic domination, hegemonic discourses - and offering alternatives for action.

Although we have no problem with critical theory, its more extreme versions risk adopting a simplified, bipolar view of the world wherein the palette of human existence is reduced to a simplistic contrast: power-holding elites versus the oppressed masses. Yet power is not a thing. It is an attribute of a relationship (Elias 1998) that may be fruitfully explored from situation to situation. Power is often contested, and economically and politically powerless people often have other means to mitigate relations with those in power, the 'weapons of the weak' (Scott 1987). The naturalistic inquiry perspective directs attention to such instances of contestation by making emic viewpoints on power central to the analysis. This may correct overly simplistic notions of power and help advocacy workers and their constituencies to be more effective. 


\section{Management consultancy and policymaking}

Management consultancy and policymaking share a positive belief in intervention, that is, in the carrying out of purposeful action in order to achieve desired changes. Most people intuitively concur with attempts to improve society through carefully crafted intervention measures, removing obstacles that block a society's advancement. However, as Robert Merton's discussion of unintended consequences warns, there is a danger of applying what appear to be straightforward, practical solutions without appreciating a society's complexities (Merton 1935; Fine 2006).

Naturalistic inquiry suggests that intervention should be considered as an additional, fourth layer of the hermeneutical model presented in Figure 2. Only if and when the three other layers have been adequately covered can an intervention be expected to work. In other words, any intervention should rest on a plausible explanation of society or the relevant part of it, which, in turn, should rest on a thorough understanding and a full description of it. Jumping straight to the intervention layer without really understanding society is - at best - like shooting ducks with buckshot. You will probably hit something, but at the risk of considerable collateral damage.

Teaching naturalistic inquiry to future policymakers and management consultants thus requires overcoming a special mental challenge: it should encourage them to postpone taking hasty action and to explore underlying layers first. They should first do a round of naturalistic inquiry that includes all stakeholders, from high to low, and seriously explore their viewpoints. Management studies have an ingrained tendency to adopt a leadership discourse, but ethnographic work in organisations time and again unveils how rank and file members of an organisation are as important as its leadership for day-to-day functioning (Weick 1995). Naturalistic inquiry allows students to gain in-depth insight into the company or organisation and to come up with solutions that are supported by that organisation as a whole instead of only by its shareholders or board. This is one reason why naturalistic inquiry has an affinity with the field of organisational studies and organisational anthropology.

On a similar note, the field of policy advice tends to subscribe to the traditional policy cycle: a linear idea of policymaking beginning with etic ('expert') analysis of a society's problems, subsequently translated into policy solutions, followed by a round of evaluations in order to adjust the original policy (Hill 2005). Policy analysis is typically based on the descrip- 
tion of a gap between a desired and an actual state of affairs. Here, too, recourse may be made to naturalistic inquiry as it builds not on etic but on emic understandings of a society's problems. The recommendation given above - to base intervention firmly on careful description, understanding, and explanation of a problem - is relevant for policy advisors too.

Lastly, naturalistic inquiry directs attention to symbolic aspects of policymaking. As Kenneth Burke has observed, politics is often 'secular prayer' (Burke 1945: 393). Speaking of planned interventions can have a highly ritual character, and policymaking may fruitfully be seen as a form of storytelling. Particular stories may rise and fall depending on the epistemic community that they succeed in recruiting (Haas 1992). Ritual aspects of policymaking are as real as formal policy objectives and practices. Consultants and policymakers do well to familiarise themselves with them.

\section{Journalism}

Journalists have much in common with qualitative social scientists. In Howard Becker's (2007) words, both practice a form of 'telling about society'. They report on the actions of ordinary and not so ordinary members of society, placing these in a larger frame of reference. Good journalistic reportage such as that found in magazines like Granta and Monthly Atlantic has a real-life quality to it, including depth, that approaches thick description. Obviously, there are also differences. Social scientists may be interested in understanding society as a whole, whereas journalists often try to uncover the wrongs of society. And journalists write for a broader audience than most social scientists do - although, arguably, social scientists should write for broader audiences too if they wish to be responsible public and engaged scholars (Burawoy 2005). Yet journalists and social scientists share the ambition to make society transparent to its members (Hannerz 2010: 201-216). Both professions try to disentangle the webs of meanings - the social constructions and the social facts - in which humans are enmeshed. Thus, the craft of naturalistic inquiry shades into the craft of the journalist.

Journalism, however, appears to face two challenges to which we believe the teaching of naturalistic inquiry could give particular attention. First, socalled experts increasingly monopolise knowledge about society. Journalists are under considerable pressure to adopt the viewpoints of such experts. The press officer, who gives the official viewpoint of a company or a politician, is 
a well-known case in point. Other examples that come to mind are the sociologist claiming expert knowledge of multicultural society and the economist advocating a particular intervention strategy. However, as Nicolas Lehmann (2017) warns us, experts are rarely the impartial observers they claim to be, and they are usually part of a discourse community. Their discourse should not be adopted at face value, instead it should be unpacked. On whose behalf are experts acting? And to what extent is their advice self-serving?

A second danger is the hyperrealism ingrained in much journalism. This parallels abstracted empiricism (Mills 1959) in the social sciences: the reification of society as it happens to be at a particular time and place. Good journalistic work, however, considers how certain points of view in a society come about. It looks for diversity, for dissenting voices that question established definitions of the situation. Qualitative literacy can be a great help.

Other examples of extra-academic, professional trajectories could be given. These examples all point in the same direction: learning the craft of naturalistic inquiry prepares graduates who work in a variety of jobs to become qualitatively literate and socially critical professionals who can contribute to societal transparency and to the emancipation of underprivileged groups in society (see also Simpson 2009).

\section{Conclusion}

We have argued here that the teaching of qualitative research in higher education is under threat. Qualitative approaches are being delegitimised by fragmentation, leading to culture wars within academia, eroded by new public management and sidelined by an uncritical belief in big data. We have stressed the importance of teaching the artisanal core of qualitative research: the craft of naturalistic inquiry. As societies are becoming more complex, more global, more unequal, and more intolerant (Mishra 2017), qualitative literacy is more important than ever, both inside and outside academia. Teaching students to ground their understandings of society in emic perspectives is imperative to arrive at a more transparent and a more just society. 


\section{Acknowledgments}

We thank the audiences of the Dutch/Flemish Sociologists' Day (Brussels 2017) and the European Congress of Qualitative Inquiry (Leuven 2018) to which we presented earlier versions of this article for sharing their valuable insights. We thank Prof. Jan Kees van Donge and two anonymous reviewers for their frank and constructive comments, and Catherine O'Dea for language editing.

Joost Beuving (MA Development Studies; PhD Economic Anthropology) is a senior lecturer and researcher at the Nijmegen Institute for Social and Cultural Science, Radboud University Nijmegen. His research interests are in the sociology of everyday economic life and in qualitative research methodology. Email: j.beuving@maw.ru.nl

Geert de Vries (MA Psychology; PhD Sociology) is emeritus Associate Professor of Sociology at the Vrije Universiteit Amsterdam and at Amsterdam University College. His research interests are historical sociology, sociology of education, social problems and qualitative research.Email: g.c.de.vries@vu.nl

\section{Notes}

1. To be fair, we know one counterexample to our argument. Dr Gerben Moerman of the University of Amsterdam has developed an inspiring series of weblectures that coordinate with and are accompanied by real-time workshops. For a sample, see https://www.youtube.com/ playlist $?$ list $=$ PLZ0df6wQ50090SF_rEQc-vQ9UOQYmeMnu.

2. See https://en.wikipedia.org/wiki/Alice_Goffman and Lewis-Kraus 2016 and the references in those articles.

3. A recent survey of the history of crafts and a passionate plea for the resurrection of craftspersonship is provided in Langlands (2018). See also Sennett (2008).

4. A 2018 survey of 318 Sociology graduates from Vrije Universiteit Amsterdam found them working in a wide variety of jobs (Zelfevaluatie 2019: 225-232). 'Researcher', 'consultant', 'Journalist/editor/ writer', 'policy advisor', and NGO-related jobs were among the more often mentioned. Most of them find jobs within the Netherlands. Graduates from Amsterdam University College more often seek and find work abroad, for example, at global NGOs. 


\section{Joost Beuving and Geert de Vries}

\section{References}

Bal, E., E. Grassiani and K. Kirk (2014), 'Neoliberal individualism in Dutch universities: Teaching and learning anthropology in an insecure environment', Learning and Teaching 7, no. 3: 46-72. https://doi.org/10.3167/latiss.2014.070303.

Becker, H. (2007), Telling about Society (Chicago: Chicago University Press).

Berger, P. and T. Luckmann [1967] (1991), The Social Construction of Reality: A Treatise in the Sociology of Knowledge (London: Penguin).

Beuving, J. and G. de Vries (2015), Doing Qualitative Research: The Craft of Naturalistic Inquiry (Amsterdam: Amsterdam University Press).

Blumer, H. (1954), 'What is wrong with social theory?', American Sociological Review 19: 3-10. https://doi.org/10.2307/2088165.

Burawoy, M. (2005), 'For public sociology', American Sociological Review 70, 1: 4-28. https://doi.org/10.1177/000312240507000102.

Burke, K. (1945), A Grammar of Motives (New York: Prentice Hall).

Cadwalladr, C. (2017), 'The Great British Brexit robbery: How our democracy was hijacked', The Observer, 7 May.

Cicourel, A. (1964), Method and Measurement in Sociology (New York: Free Press).

Collier, P. (2007), The Bottom Billion: Why Poor Countries are Failing and What Can Be Done about It (Oxford: Oxford University Press).

Dodge, J., R. Holtzman, M. van Hulst and D. Yanow (2016), 'What does it mean to teach “interpretively”?' Learning and Teaching 9, no. 1: 73-84. https://doi.org/10.3167/ latiss.2016.090105.

Elias, N. (1998), On Civilization, Power and Knowledge, S. Mennell and J. Goudsblom (eds) (Chicago: Chicago University Press).

Fine, G. (2006), 'The chaining of social problems: Solutions and unintended consequences in the Age of Betrayal', Social Problems 53, no. 1: 3-17. https://doi.org/10.1525/ sp.2006.53.1.3.

Geertz, C. (1993), The Interpretation of Cultures (London: Fontana).

Glaser, B. and A. Strauss (1967), The Discovery of Grounded Theory: Strategies for Qualitative Research (Chicago: University of Chicago Press).

Goffman, A. (2014), On the Run: Fugitive Life in an American City (Chicago: University of Chicago Press).

Grassegger, H. and M. Kocerus (2017), 'The data that turned the world upside down', Motherboard 28 January. https://motherboard.vice.com/en_us/article/mg9vvn/ how-our-likes-helped-trump-win.

Guba, E. and Y. Lincoln (1982), 'Epistemological and methodological bases of naturalistic inquiry’, Educational Communication and Technology Journal 30: 233-252. https:// doi.org/10.1007/BF02765185. 
Haas, P. (1992), 'Epistemic communities and international policy coordination', International Organization 46, no. 1: 1-36. https://doi.org/10.1017/S0020818300001442.

Habermas, J. (1984), The Theory of Communicative Action, Vol. 1: Reason and Rationalisation of Society, trans. Thomas McCarthy (Boston: Beacon Press).

Halford, S. and M. Savage (2017), 'Speaking sociologically with Big Data: Symphonic social science and the future for Big Data research', Sociology 51, no. 6: 1132-1148. https://doi.org/10.1177/0038038517698639.

Hannerz, U. (2010), Anthropology's World (London: Pluto).

Hill, M. (2005), The Public Policy Process, 4th ed. (Harlow: Pearson).

Hood, C. (1991), 'A public management for all seasons', Public Administration 69: 3-19. https://doi.org/10.1111/j.1467-9299.1991.tb00779.x.

ITU Telecommunication Development Bureau (2015), The World in 2015: Facts and Figures (Geneva: ITU).

Kaplan, A. (1964), The Conduct of Inquiry: Methodology for Behavioural Science (San Francisco: Chandler).

Krause-Jensen, J. and C. Garsten (2014), 'Neoliberal turns in higher education', Learning and Teaching 7, no. 3: 1-13. https://doi.org/10.3167/latiss.2014.070301.

Langlands, A. (2018), Craeft: An Inquiry into the Origins and True Meaning of Traditional Crafts (New York: Norton \& Co).

Lehmann, N. (2017), The Journalistic Method, http://c-lab.columbia.edu/0199.html (accessed 3 March 2017).

Lewis-Kraus, G. (2016), 'The Trials of Alice Goffman', New York Times Magazine, 12 January.

Lindstrom, M. (2016), Small Data: The Tiny Clues that Uncover Huge Trends (New York: St. Martin's Press).

Malinowski, B. (1978), Argonauts of the Western Pacific: An Account of Native Enterprise and Adventure in the Archipelagos of Melanesian New Guinea (New York: Routledge).

Mayer-Schönberger, T. and D. Cukie (2013), Big Data: A Revolution that Will Transform How We Live, Work, and Think (London: John Murray).

Merton, R. (1935), 'The unintended consequences of purposive social action', American Sociological Review 1, no. 6: 894-904.

Mills, C. W. (1959), The Sociological Imagination (Oxford: Oxford University Press).

Mishra, P. (2017), The Age of Anger: A History of the Present (New York: Allan Lane).

Nash, K. (2018), 'Neo-liberalisation, universities and the values of bureaucracy', The Sociological Review 67, no. 1: 178-193. https://doi.org/10.1177/0038026118754780.

Neisser, U. (1976), Cognition and Reality (San Francisco: Freeman \& Co).

O’Dell, T. and R. Willim (2015), 'Rendering culture and multi-targeted ethnography', Ethnologia Scandinavica 45: 89-102. 
Power, M. (1997), The Audit Society: Rituals of Verification (Oxford: Oxford University Press).

Scott, J. (1987), Weapons of the Weak: Everyday Forms of Peasant Resistance (New Haven, CT: Yale University Press).

Scott, J. (1998), Seeing Like a State: How Certain Schemes to Improve the Human Condition Have Failed (New Haven, CT: Yale University Press).

Sennett, R. (2008), The Craftsman (New Haven, CT: Yale University Press).

Shear, W. and A. Zontine (2010), 'Reading neoliberalism at the university', Learning and Teaching 3, no. 3: 32-62. https://doi.org/10.3167/latiss.2010.030303.

Simmel, G. (1950), The Sociology of Georg Simmel, Kurt H. Wolf (ed) (Glencoe: Free Press).

Simpson, B. (2009), 'Citizenship, craft and the making of Mode Two citizens?', Learning and Teaching 2, no. 3: 98-105. https://doi.org/10.3167/latiss.2009.020306.

Small, M. L. (2018), 'Rhetoric and evidence in a polarized society', public lecture, ISERP, Columbia University, 1 March, https://www.russellsage.org/sites/default/files/ MLSmall_Qualitative2018.pdf.

Spradley, J. (1980), Participant Observation (New York: Holt, Rinehart and Winston).

Swedberg. R. (2016), 'Before theory comes theorizing or how to make social science more interesting', British Journal of Sociology, 67, no. 1: 5-22. https://doi.org/10.1111/ 1468-4446.12184.

Strauss, A. and J. Corbin (1998), Basics of Qualitative Research: Techniques and Procedures for Developing Grounded Theory (London: Sage).

Thomas, W. and D. Thomas (1928) The Child in America: Behavior Problems and Programs (New York: Knopf).

Van Krieken, R. (2012), 'On the celebrification of the Academy', Global Dialogue: Newsletter for the International Sociological Association 2, no. 4: 6-7.

Wang, T. (2016), 'Why big data needs thick data', Ethnograpy Matters, 20 January, https:// medium.com/ethnography-matters/why-big-data-needs-thick-data-b4b3e75e3d7.

Weber, M. (1947), The Theory of Social and Economic Organization (New York: Free Press).

Weick, K. (1995), Sensemaking in Organizations: Foundations for Organizational Science (London: Sage).

Wright, S. and A. Rabo (2010), 'Introduction: Anthropologies of university reform', Social Anthropology 18, no. 1: 1-14. https://doi.org/10.1111/j.1469-8676.2009.00096.x.

Wright, S. and J. Williams-Ørberg (2008), 'Autonomy and control: Danish university reform in the context of modern governance', Learning and Teaching 1, no. 1: 27-57. https://doi.org/10.3167/175522708783113550.

Zelfevaluaties Bachelor- en Masteropleiding Sociologie Vrije Universiteit Amsterdam (2019). Amsterdam: Vrije Universiteit.

Zussman, R. (2004), 'People in places', Qualitative Sociology 27, no. 4: 351-363. 